been determined, to identify with reasonable assurance the genus to which it belongs.

The bulk of the book consists of generic descriptions of selected genera. In each instance these follow a precise pattern, setting out the type species, then a concise and clear generic description followed by those diagnostic features which particularly characterize the genus in question. These two sections are most useful. Then follow notes on certain species within the genus. As one reads through the text, it is interesting to see how wide has been the author's search for information about the occurrence of a particular species. He has not confined his attention to records from soil, but occasionally mentions species growing on substrates outside the soil.

The book is clearly printed and the illustrations are of the very highest quality. The author is to be congratulated on having prepared an outstanding work of reference for general mycological laboratories, and particularly for those laboratories dealing more specifically with fungi isolated from soil. The publishers are to be congratulated on the excellence of the format of the work. I recommend this book as one of the most outstanding mycological texts in recent years.

C. G. C. Chesters

\section{TITANIUM AND VANADIUM}

\section{The Chemistry of Titanium and Vanadium.}

An Introduction to the Chemistry of the Early Transition Elements. By R. J. H. Clark. (Topies in Inorganic and General Chemistry Monograph 11.) Pp. xi+327. (Elsevier: Amsterdam, London and New York, 1968.) 155s. IN writing this monograph Dr Clark has brought together a considerable amount of information in what is generally a pleasing and authoritative manner.

After a brief introduction the halides and oxyhalides of titanium and vanadium are discussed (chapter two). The emphasis is on the preparative routes available, and many physical data, including thermodynamic functions and structural parameters, are included in tabular form.

Chapters three to six inclusive are concerned with the coordination complexes of titanium and vanadium, the primary classification of which is made according to the formal oxidation level of the metal. This is without doubt the most useful part of the book, especially the description (chapter six) of the spectroscopic and magnetic properties of these compounds.

The remaining chapters are devoted to a discussion of the oxo species (chapter seven), organometallic compounds (chapter eight), oxides and chalconides (chapter nine), and other topics (chapter ten, which includes sections on the alkoxides and analytical methods). In these chapters the author was faced with a considerable task in effecting a distillation of an extensive literature, particularly that appertaining to Ziegler-Natta catalysis and the alkoxides. By referring to more comprehensive works the author has succeeded in producing a very clear account of these areas without the loss of too much necessary detail. At times, however, the text does become somewhat vague, such as when the author states that siloxanes "of the type $\mathrm{VO}\left(\mathrm{OSiR}_{3}\right)_{3}$ may be prepared by at least eight different methods starting from $\mathrm{VOCl}_{3}, \mathrm{~V}_{2} \mathrm{O}_{5}$ or orthovanadates" without further explanation.

On the whole the typographical layout is good and errors are few. In the earlier chapters there is a tendency to quote references referred to in tables directly beneath the table. This leads to untidiness and in some cases repetition; for example, four of the references quoted beneath Table 18 are repeated, with different numbers, in the collected bibliography at the end of the chapter. References to the 1967 literature are included.

This book maintains the general high standard set by the previous works, but unfortunately the price will restrict it to libraries and rich chemists only.

\section{ESSAYS ON GEOMAGNETISM}

\section{Sydney Chapman-Eighty-from his Friends}

Edited by Syun-Ichi Akasofu, Benson Fogle and Bernhard Hourwitz. Pp. xiii +230 . (University of Colorado Press: Boulder, Colorado, 1968.) \$2.95 paper; $\$ 5.95$ boards. Physics of Geomagnetic Phenomena

Edited by S. Matsushita and Wallace H. Campbell. (International Geophysics Series.) Vol. 1. Pp. xvii +623. 252s. Vol. 2. Pp. xvii +625-1398. 270s. (Academic Press: London, 1967.)

I SUSPECT that many eminent old gentlemen have been embarrassed on their eightieth birthdays by the presentation of Festschriften containing essays by clever young men which are supposed to be connected with halfremembered work of their own, but which are largely unintelligible to them. Professor Chapman is doubly protected from this embarrassment: at eighty he is still the leading authority and the most learned man in his field, and his Festschrift is of a new kind. It contains a few brief essays setting out his work in relation to what has happened since; three fascinating autobiographical pieces, some pictures, a bibliography and about two hundred reminiscences and anecdotes written by his friends. No more charming tribute to a great scientist and a humane and distinguished man can be imagined. Chapman's life spans the whole period of the development of geophysics from the great Victorians, including Schuster and Osborne Reynolds who were on the staff at Manchester when he was a student, to the present age of alphabetical agencies, NASA, NERC and the rest.

One of Chapman's most influential achievements was the 1,000 page treatise, Geomagnetism, which he and Julius Bartels published in 1939. This book gathered together and systematized all that was known about the Earth's magnetic field and its relations with the Sun. Now, after thirty years, there are gaps, a new book is clearly needed and this Matsushita and Campbell have attempted to provide. They have not replaced "Chapman and Bartels"; they do not repeat all the basic developments to be found there, they build on them to show the present state of the subject. Inevitably, they did not write the book themselves; there are twenty-four chapters by twenty-three authors.

The first volume opens with a historical review by Chapman; the earlier part covers well known ground but later, dealing with events in which he participated, is of considerable interest. Following this are chapters on instruments, geomagnetic indices, palaeomagnetism, the main geomagnetic field and induction within the Earth, which occupy about three hundred pages. This material provides a background for the main theme of the book which is the short period variations of the field and their relation to the ionosphere, the aurora, the radiation belts, the magnetosphere, interplanetary space and the Sun. The article on palaeomagnetism by Nagata and Ozima is notable for a detailed and useful discussion of the magnetic properties of rocks; the recently discovered relation between reversals of the field, the magnetic pattern at sea and spreading of the ocean floor is not mentioned; presumably its importance was not appreciated in the United States until after the work was in press. Price's review of electromagnetic induction is an accurate and thorough treatment of a subject of growing importance on which misapprehensions are common.

The rest of the first volume is concerned with the daily variation (by Matsushita), variations in the equatorial zone (by Onwumechilli) and the ionosphere at times of small disturbance.

The second volume is concerned with magnetic disturbances and their relation to phenomena in space. It includes a review of geomagnetic storms and auroras by Akasofu and Chapman. The main influence has shifted from the description of events at the surface of the Earth, 